\title{
A Rare Case of Anterior Iliac Blade Osteochondroma in a 22 Year Old Male: A Case Report
}

Mohammed Danfulani*, Abubakar Musa, Shamsuddeen Ahmad Aliyu, Ibrahim Haruna Gele, Sule Muhammed Baba Department of Radiology, Faculty of Clinical Sciences, Usmanu Danfodiyo University Sokoto, Nigeria

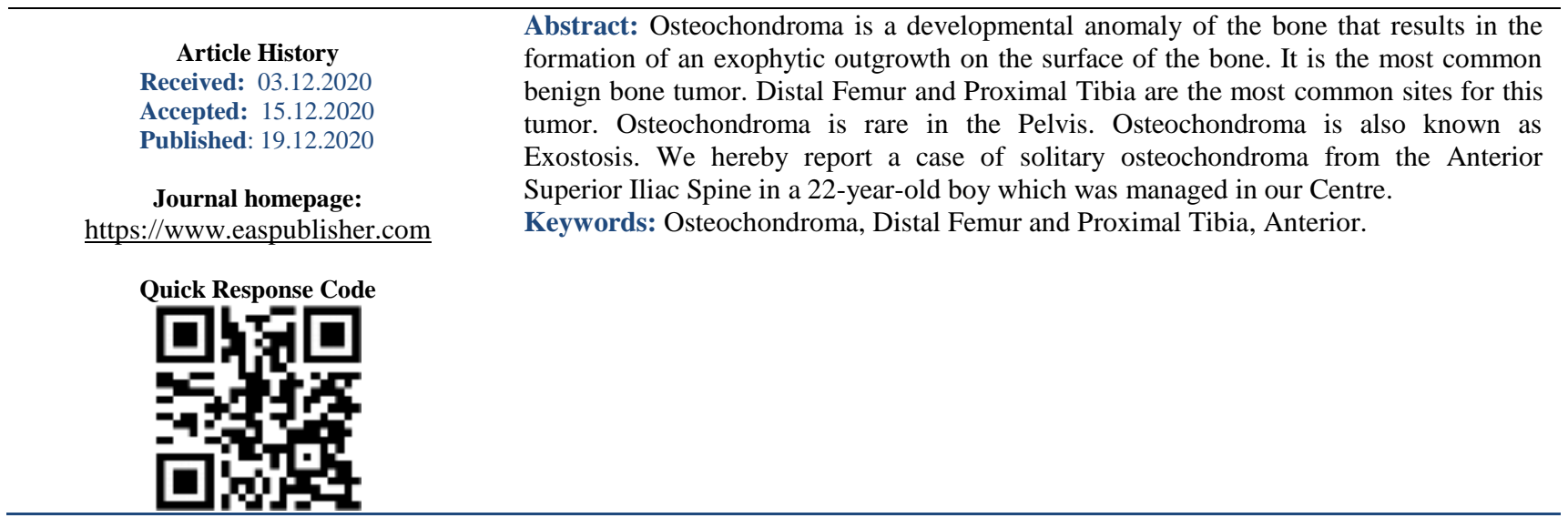

Copyright (C) 2020 The Author(s): This is an open-access article distributed under the terms of the Creative Commons Attribution 4.0 International License (CC BY-NC 4.0) which permits unrestricted use, distribution, and reproduction in any medium for non-commercial use provided the original author and source are credited.

\section{INTRODUCTION}

Osteochondroma are cartilage covered histologically normal bony projections (exostoses) on the external surface of a bone in the vicinity of growth plates. It can be solitary or multiple, pedunculated or sessile, symptom less or cause morbidity by the associated deformity, neurovascular compromised and malignant changes [1]. It is found generally in long bones in $60 \%$ and short tubular bones in $10 \%$. Flat bones are rarely affected, however a small percentage is found in the axial andother flat bones [2]. Males are more affected than female with a ration of 2:1 [1]. The exact etiology of the growth is not known but the peripheral portion of the epiphysis is thought to herniate from the growth plate [3]. The herniation may be idiopathic or may be the result of trauma or a perichondrial ring deficiency resulting in abnormal extrusion of metaplastic cartilage that responds to the factors that stimulate growth plate and this result to exostosis growth [3]. This reported case is of interest because of the rarity and the important role plain radiography plays in its management.

\section{Case Report}

A 22year old male student presented with complaint of swelling in his right hip joint region for about nine months that was painless but now associated with reduced range of movement of the right hip joint and grasping sensation of the overlying skin. $\mathrm{He}$ attributed the swelling to have started when he fell on his right hip while playing football about nine months. There was no history of fever, loss of appetite or loss of weight. The past medical history and drug history were insignificant.

On examination the vital sign were essentially normal. Musculoskeletal examination revealed a hard protruded mass from the right upper thigh that is attached to the underlying structure; the mass is non tender, no change in the overlying skin. No regional lymphdenopathy. There was some restriction of the right hip joint movement. Power of both limb were normal. Other systemic examination was essentially normal. A provisional clinical diagnosis of a right upper thigh mass was made. Patient was requested to do x-ray of the pelvis and both hips.

Plain radiograph shows a pundunculated tubular bony outgrowth from the right anterior iliac blade that shows medullary and cortical continuity with the iliac bone with well defined outline Fig-1. There was a cluster of calcification at the distal part of the lesion extending in to the soft tissue Fig-3. At the cartilaginous distal part of the lesion is a lucent rim area Fig-2, and the cartilage cap measured $2.5 \mathrm{~cm}$. On the basis of radiographic findings an impression of solitary 
penduncuatedosteochondroma was made with suspicion of malignant transformation and patient was advised to do computed tomography (CT) scan of the pelvis. The patient was not able to do the examination due to his poor socioeconomic status. He subsequently had surgery with the mass removed and histology report shows fragment of osteoid and cartilage with numerous plasma cells and giant cells which confirmed the lesion to be benign osteochondroma and inflammatory process and no features of malignant changes. Patient has been doing well at post up follow up.

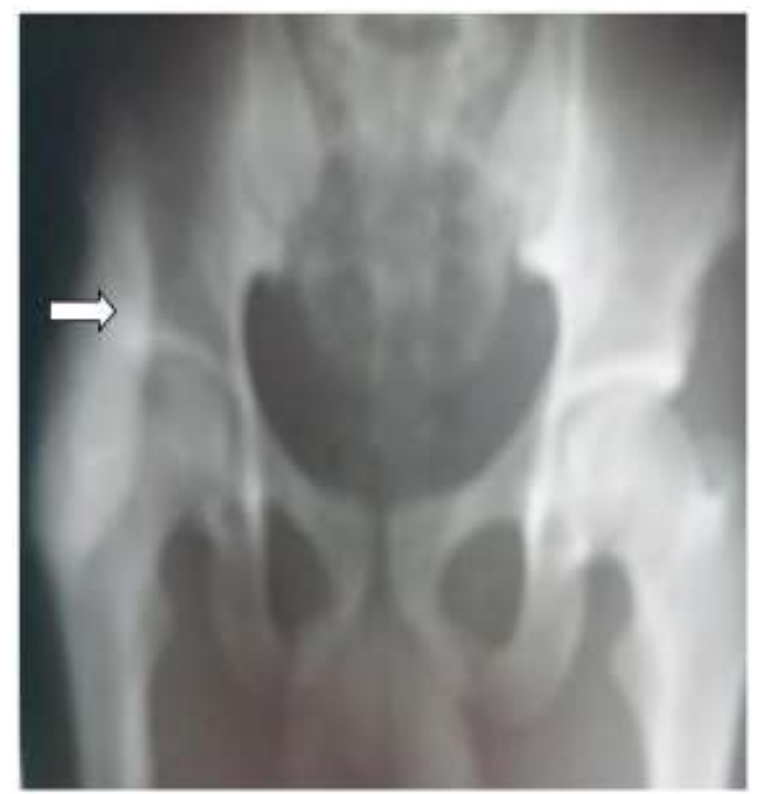

Fig-1: An AP radiograph of the pelvis showed a bony projection (arrow) from the right anterior iliac blade toward the hip joint supper imposed on the joint

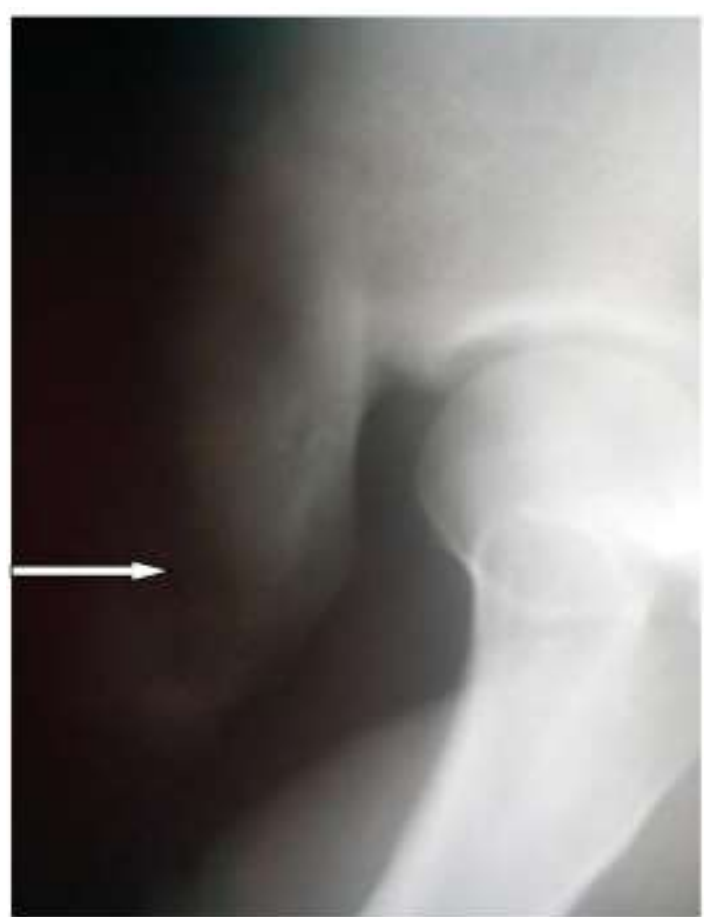

Fig-2: Oblique view of the right hip showed the bony projection with continuity of its medullary cavity with the parent bone (Ilium) in profile. A rim of horizontal lucent area noted (arrow)

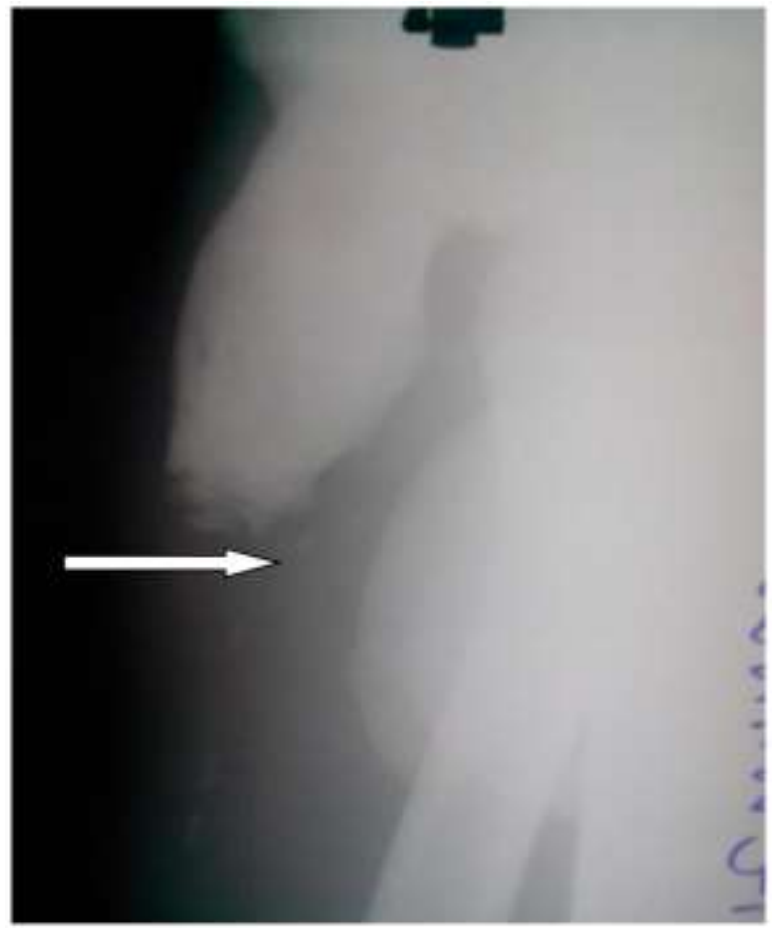

Fig-3: Oblique view of the right hip joint (soft tissue factor) showed calcification at the cartilaginous end of the bony protrusion with extension in to soft tissue.

\section{DiscuSSION}

Osteochondroma is also referred to as exostosis or osteocartilagenous exostosis which account for $30-50 \%$ of all bony neoplasm [4]. Majority of patients present within the first three decades [2]. Osteochondroma occurs in $3 \%$ of the general population. There is a male preponderance with the male to female ratio of 2:1 [1].

Each individual with oeteochondroma may experience symptoms differently and most of the time individual will experience no symptom. Some of the most common symptoms are hard immobile painless palpable mass, adjacent muscle soreness and pressure or irritation with exercising [3].

We are reporting this case due to the rarity of this lesion in the flat bone and the diagnostic value of plain radiography in making diagnosis.

Osteochondroma is found generally in the long bones as it occurs in area of endochondral bones ossification [2]. The long tubular bone is $60 \%$ (femur common site) and short tubular bones in $10 \%$. However, a small percentage is also found in the axial skeleton and other flat bones including skull and facial bones. Scapular $4 \%$, pelvic $5 \%$ and spine $2 \%$ lesion form the majority of these [1]. Flat bones are rarely affected [4]. Cristal border of ilium is a rare but not unusual site for osteochondroma. In the flat bone osteochondroma usually arises in the part must recently formed from cartilage, these area being analogous to the more distinctive metaphyses of the appendicular long 
bones. In the scapular these areas are along the inner borders while in ilium these are along the iliac crest and around the acetabulum [2].

Plain radiography is generally sufficient for diagnosis and follow-up [1]. High imaging modalities are needed when complication arises or malignant changes are suspected [5]. In osteochondroma of flat bones with complex anatomy and sessile lesion, the continuity and thus the diagnosis may not be apparent on the radiograph alone. Hence higher imaging may be required [5].

Plain radiograph is often diagnostic because the radiological features are often pathognomonic, making diagnosis easy [6]. The most characteristic features being the extension of the medullary canal of the parent bones into the osteochondroma [2]. Radiologically two distinct forms of osteochondroma can be recognized i.e. sessile and pedunculated [5]. Osteochondroma that has stalk are defined as pedunculated while broad base of attachment considered as sessile [1]. Whether sessile or pendunculated the medulary canal of the bone cortex are in continuity. The lesion also varies widely in size and numbers [5].

The cartilage cap measurement is important for osteochondromas ${ }^{7}$. In a study by Hudson showed that the thickness of the cartilage cap in benign osteochondroma average $9 \mathrm{~mm}$, with a maximum of $2.5 \mathrm{~cm}$ and for malignant transformation mean measurement is $3.9 \mathrm{~cm}$ [8]. The suspicion of malignancy is indicated by growth of the tumour after puberty, presence of pain or thickness of the cartilage cap over $1 \mathrm{~cm}$, extensive calcification, and irregularities with the cartilage mantle, erosion or destruction of adjacent bones in adult [7].

Ultrasound helps in determine the thickness of the cartilaginous cap, if it continues to grow after skeletal maturity [2]. CT scan is also a very good modality for demonstrating the cartilaginous cap while MRI is the imaging modality of choice for evaluating the thickness of the cartilaginous cap. Normally the cap is a few millimeters thick in adult and any thickness more than $2 \mathrm{~cm}$ should be view suspiciously [5].

Definite diagnosis is usually established on histological examination [2]. The presence of hyaline cartilaginous cap covering over the bone is diagnostic [5]. Malignant transformation into chondrosarcoma is seen in $1 \%$ of cases with solitary lesion and $5 \%$ of cases in multiple hereditary exostoses. Radiological sign of malignant transformation includes focal radiolucencies and destruction of the adjacent bones [9].

\section{SUMMARY}

We reported a case of iliac blade osteochondroma from the Anterior Superior Iliac Spine in a 17-year-old patient that was diagnosed by plain radiolgraph and histological confirmation. The patient was managed by en bloc resection; thus highlighting the role of plain radiography in evaluating bone tumours.

\section{REFERENCE}

1. Kumar, S., Shah, A. K., Patel, A. M., \& Shah, U. A. (2006). CT and MR images of the flat bone Osteochondromata from head to foot: A pictorial essay. Indian J Radiol Imaging, 16:589-96. Available from: https://www.ijri.org/text.asp?2006/16/4/589/32277

2. Schmale, G. A., Conrad, E. U., \& Raskind, W. H. (1994). The natural history of hereditary multiple exostoses. J Bone Joint Surg Am; 76(7), 986-92. doi: 10.2106/00004623-199407000-00005. PMID: 8027127.

3. Aldashash, F., \& Elraie, M. (2017). Solitary osteochondroma of the proximal femur causing sciatic nerve compression. Annals of Saudi medicine, $\quad 37(2), \quad 166-169$. https://doi.org/10.5144/0256-4947.2017.166

4. Javdan, M., Hekmatnia, A., Ghazavi, A., Basiratnia, R., Mehrzad, M., Hekmatnia, F., \& Ahrar, H. (2015). A case report of osteochondroma with unusual clinical and imaging presentation. Advanced biomedical research, 4(2), 1-4. https://doi.org/10.4103/2277-9175.148258

5. Obalum, D. C., Eyesan, S. U., Ezembakwe, M. E., \& Abdulkareem, F. B. (2008). Pattern of osteochondroma in Lagos, Nigeria. Nig Q J Hosp Med, 18:16-21. DOI: 10.4314/nqjhm.v18i2.44984

6. Özkan, E. A., Göret, C. C., Özdemir, Z. T., Yanık, S., Doğan, M., Gönültaş, A., \& Akkoca, A. N. (2015). Pattern of primary tumors and tumor-like lesions of bone in children: retrospective survey of biopsy results. International journal of clinical and experimental pathology, 8(9), 11543-11548. https://www.ncbi.nlm.nih.gov/pmc/articles/ PMC4637704/

7. Murphey, M. D., Choi, J. J., \& Kransdorf, M. J. (2000). Imaging of osteochondroma: Variants and complications with radiologic- pathologic correlation. Radiographic, 20(20) 1407-1434. DOI: 10.1148/radiographics.20.5.g00se171407.

8. Hudson, T. M., Springfield, D. S., \& Spanier, S. S. (1984). Benign exostoses and exostochondromas: Evaluation of cartilage thickness by CT. Radiology, 592-599.

9. Vanhoenacker, F. M., Van Hul, W., Wuyts, W., Willems, P. J., \& De Schepper, A. M. (2001). Hereditary multiple exostoses: from genetics to clinical syndrome and complications. European journal of radiology, 40(3), 208-217. 